\title{
Benthic foraminifera from part of Andhra coast, Southeast coast of India: An integrated approach for marine environmental changes
}

\author{
SREENIVASULU G AND JAYARAJU N
}

Yogi Vemana University

Presenting Author: seenu9441@gmail.com

Metals are continuously released into the biosphere by volcanoes, natural weathering of rocks and also by numerous anthropogenic activities, such as mining, combustion of fuels, industrial and urban sewage and agricultural practices. Many of these metals are essential to our health and well-being of the organisms that live on our planet, including ourselves. However, if excess amounts of these metals are allowed to accumulate in our natural environments, the consequences can lead to a number of problems including sediment contamination, ecosystem contamination, a loss of aquatic life and even severe human health issues. Biological monitoring using bioindicators, enables the detection of unforeseen impacts and is more directly related to the "ecological health" of an ecosystem than based on chemical data. The present study was carried out at Tupilipalem, which may likely to be developed as a major sea port as Dugarajapatnam port by the Government of India. The Landsat 8 OLI/TIRS data shows periodic closure of lagoon mouth for short periods, impacting ecological characteristics and the faunal distribution. The study identified a total of 62 benthic foraminiferal species belonging to 23 genera and 3 suborders. The Tupilipalem ecosystem contains significant metal pollutant levels due to human interferences such as aquaculture, industrial and harbor activities. This study attempts to relate the abundance of foraminifera to heavy metal concentrations viz. $\mathrm{Fe}, \mathrm{Mn}, \mathrm{Cr}$, $\mathrm{Cu}, \mathrm{Ni}, \mathrm{Pb}, \mathrm{Zn}$ and $\mathrm{Cd}$. The heavy metals were assessed by factor analysis and hierarchical cluster analysis, and the results showed both positive and negative correlations among the analyzed heavy metals. Sediment pollution assessment was determined using Geoaccumulation Index (Igeo), Enrichment Factor (EF), and Pollution Load Index (PLI), and the results show significant seasonal differences in metal concentrations and prevalence of higher concentrations of many metals in the sediments. This study also discusses how the coastal morphology affecting heavy metal concentrations as well as the ecology and distribution of benthic foraminifera. 